\title{
Use of procalcitonin for the differential diagnosis of fever in cancer patients: an observational study
}

\author{
Daria Macchioni, ${ }^{1}$ Giuseppe Chesi, ${ }^{1}$ Luca Cottafavi, ${ }^{1}$ Paola Loria,,${ }^{2}$ Amedeo Lonardo, ${ }^{2}$ Mauro Maurantonio ${ }^{2}$ \\ ${ }^{1}$ Medicina Interna e Day Hospital Oncoematologico, Ospedale Magati di Scandiano AUSL Reggio Emilia; ${ }^{2}$ UO Medicina ad \\ indirizzo Metabolico/Nutrizionistico, Nuovo Ospedale Civile S. Agostino-Estense, Modena, Italy
}

\begin{abstract}
Fever often occurs in cancer patients and the possibility of having a reliable marker for the differential etiological diagnosis is desirable. The aim of this study was to investigate the eligibility of the use of procalcitonin (PCT) in hemato-oncological patients for the differential diagnosis of fever. We prospectively enrolled 98 cancer patients and divided them into two groups: those with active disease and those with non-active disease. Procalcitonin was dosed at Time 0 (recruitment) and at the onset of fever. On enrollment, PCT values were $0.1 \mathrm{ng} / \mathrm{mL}$ in $83 \%$ patients with active disease, and lower than $0.5 \mathrm{ng} / \mathrm{mL}$ in $23 \%$, which is usually considered not suggestive of bacterial infection. Four percent of patients had values over $0.5 \mathrm{ng} / \mathrm{mL}$ and these were mainly patients with neuroendocrine tumors or affiliates. On enrollment, there were also no statistically significant differences in PCT values between the two groups of patients. This showed that active cancer is unable by itself to change PCT levels. In the active disease group, 21 episodes of fever due to bacterial infection were registered, and in all of them an increase in PCT values was observed. This demonstrates the ability of PCT to detect an infection-induced fever in cancer patients. Procalcitonin concentrations are not significantly altered by active neoplastic disease. On the contrary, in the course of fever due to a bacterial infection, PCT values increase and can, therefore, be considered a useful tool in the differential diagnosis between infection-induced fever and drug-related or tumor associated-fever. Procalcitonin may be a useful marker of bacterial infection even in cancer patients.
\end{abstract}

\section{Introduction}

Patients affected by either hematologic or solid malignancy may present sporadic or persistent fever, especially during chemotherapy treatment (well known for its immunosuppressive induced status) or in the later stages of the disease. Moreover, these patients are potential candidates for the development of very severe infections. Therefore, fever in such pa-

Correspondence: Daria Macchioni, Medicina Interna, Geriatria Ospedale di Guastalla, Via Donatori di Sangue 1, Guastalla (RE), Italy.

Tel. +39.347.9454457.

E-mail: daria.macchioni@ausl.re.it

Key words: procalcitonin, C-reactive protein, cancer, infection.

Acknowledgments: our special thanks to Dr. C. Mannucci for her support in article translations.

Conflict of interests: the authors declare no potential conflict of interests.

This work is licensed under a Creative Commons Attribution NonCommercial 3.0 License (CC BY-NC 3.0).

CCopyright D. Macchioni et al., 2013

Licensee PAGEPress, Italy

Italian Journal of Medicine 2013; 7:166-171

doi:10.4081/itjm.2013.166 tients is extremely common and can have various causes that are not always easy to recognize, e.g. infections, tumor-associated, drug-related, or of unknown origin. ${ }^{1}$ It would be extremely risky and potentially fatal to continue chemotherapy without treating an infection, whereas it would be unappropriate to discontinue chemotherapy in the event of a tumor-related fever since the treatment of choice would be based on steroids. Procalcitonin (PCT) is a protein which is produced by $\mathrm{C}$ cells in the thyroid gland and then converted into its active form, calcitonin. Its plasma concentration levels increase drastically during bacterial infection. ${ }^{2,3}$ For this reason, PCT can be considered a promising marker for detecting a bacteremia. The use of PCT as a marker of bacterial infection has been demonstrated and validated by several studies, especially in the event of severe sepsis, septic shock and in lower respiratory tract infection. ${ }^{4-7}$ Data are not so convincing and sometimes even become controversial when applied to other pathological areas, such as oncology. When it comes to cancer, each clinical situation differs from another, depending on the kind of tumor, its histology, and the treatment received or ongoing for the malignancy. It becomes, therefore, difficult to choose how best to use a marker such as PCT. In this study, we first assessed PCT levels in a group of oncology patients without fever in order to see if the cancer itself, whether in remission, metastatic or in the active phase, could alter this test and, therefore, make PCT inadequate for discriminating be- 
tween fever related to a bacterial infection and fever that is tumor-induced.

The second aim of our study was to verify if there was any significant differences between PCT values within two groups of patients: one in the remission phase and one in the active phase.

Finally, our last aim was to test whether PCT could be a marker for fever related to a bacterial infection in patients with fever and active malignancy.

\section{Materials and Methods}

\section{Study design}

In order to assess whether cancer could per se affect the results, procalcitonin levels were first assessed in a group of oncology patients without fever. We then examined whether there were any significant differences in procalcitonin values between two groups of patients: active versus non-active phase. Finally, we evaluated whether procalcitonin could be a marker of bacterial infection in patients with fever and active malignancy.

From July 2009 to October 2010, we carried out a prospective evaluation of 98 patients who came to the Oncology Day Hospital of Scandiano, Reggio Emilia, northern Italy.

\section{Study population}

We enrolled patients who fell into one of 2 categories: i) active disease group: including patients with first diagnosis, a relapse of malignancy or with metastatic localization irrespective of whether they were undergoing chemotherapy or palliative care treatment; ii) non-active disease group: including patients in post-treatment follow-up surveillance without any clinical or radiological signs of active disease.

Patients presenting with fever or any clinical complications (such as distal deep vein thrombosis) or already taking antibiotics were excluded from the study.

This study was carried out in accordance with the ethical standards established by the Declaration of Helsinki, and informed consent was obtained from all participants before enrollment in the study.

\section{Study protocol}

A blood sample to evaluate PCT and C-reactive protein (CRP) values, a hemoculture and a urine culture were taken from each patient at enrollment (Time $0)$. A chest X-ray and an abdominal ultrasound were also carried out.

\section{Follow up}

In the event of onset of fever $\left(>38^{\circ} \mathrm{C}\right.$ for at least $24 \mathrm{~h}$ ) a PCT, CRP assay and two blood cultures were performed. The hemocultures were taken either from two different peripheral veins or from a central vein in those patients with a Port-a-Cath device. Imaging or other laboratory tests were performed according to symptoms and physical examination. Therefore, a urine culture was taken in case of dysuria, while a chest X-ray was performed in the presence of dyspnea or coughing, and an abdominal ultrasound was performed in case of gastrointestinal symptoms. Based on clinical and laboratory examination, empirical antibiotic therapy was prescribed if there was suspicion of bacterial infection or steroid therapy if the diagnostic orientation was one of a paraneoplastic fever.

\section{Normal range}

PCT values were considered normal up to 0.1 $\mathrm{ng} / \mathrm{mL}$; upper limit of normality for CRP was 0.5 $\mathrm{mg} / \mathrm{dL}$. PCT values over $0.5 \mathrm{ng} / \mathrm{mL}$ were considered suggestive of bacterial infection, as in most trials.

\section{Quantitative determination of procalcitonin}

We used the Liaison Brahms PCT analyzer [DiaSorin, Saluda (VC), Italy] as assay technique to determine PCT values. Sensitivity range varied from 0.1 to $500 \mathrm{ng} / \mathrm{mL}$.

\section{Statistical analysis}

Data are presented by descriptive statistical methods: means, percentages range, box plots. Statistical data from the two patients' groups were compared using Student's t-test.

\section{Results}

\section{Patients' characteristics}

The active disease group was made up of $76 \mathrm{pa}-$ tients: 44 females and 32 males. Median age was 65 years (range 35-88). Six patients suffered from hematologic disease. The remaining 70 patients were affected by a solid tumor, essentially in advanced stage. Colorectal cancer was the most represented, followed by breast cancer and small cell lung carcinoma. Five patients were enrolled at diagnosis, seventy were undergoing chemotherapy treatment and one patient was receiving palliative care (Table 1).

The non-active disease group was made up of 22 patients: 17 females and 5 males. Median age was 63 years (range 35-86). One patient presented a hematologic disease while the remaining had a solid tumor (Table 2).

\section{Procalcitonin and C-reactive protein values}

The mean baseline PCT in patients with active disease was $0.15 \mathrm{ng} / \mathrm{mL}$ (range 0.1-1.19). Eighty-three 
percent of patients in this group had a PCT equal to 0.1 . Three patients $(4 \%)$ out of 76 showed baseline PCT values of $0.5 \mathrm{ng} / \mathrm{mL}$ or over (cut off for the diagnosis of probable bacterial infection): 2 had small cell lung carcinoma, and the third pulmonary adenocarcinoma (Figure 1). A comparison of the average PCT values among the different subtypes of cancer seemed to suggest that lung cancer (both small cell and nonsmall cell) has a higher baseline PCT value than that found in other forms of cancer. The mean baseline value of CRP in patients with active disease was 2.11 $\mathrm{mg} / \mathrm{dL}$ (range 0.009-16.8 mg/dL). Fifty-three percent of patients had values over $0.5 \mathrm{mg} / \mathrm{dL}$, in most cases up to 5 times the normal value.

The small cell lung cancer presented the highest mean value of PCR when compared to other forms of cancer. In the group with active disease, the average PCT value was $0.1 \mathrm{ng} / \mathrm{mL}$ (range 0.1-0.2), while the

Table 1. Patients' characteristics: active disease group.

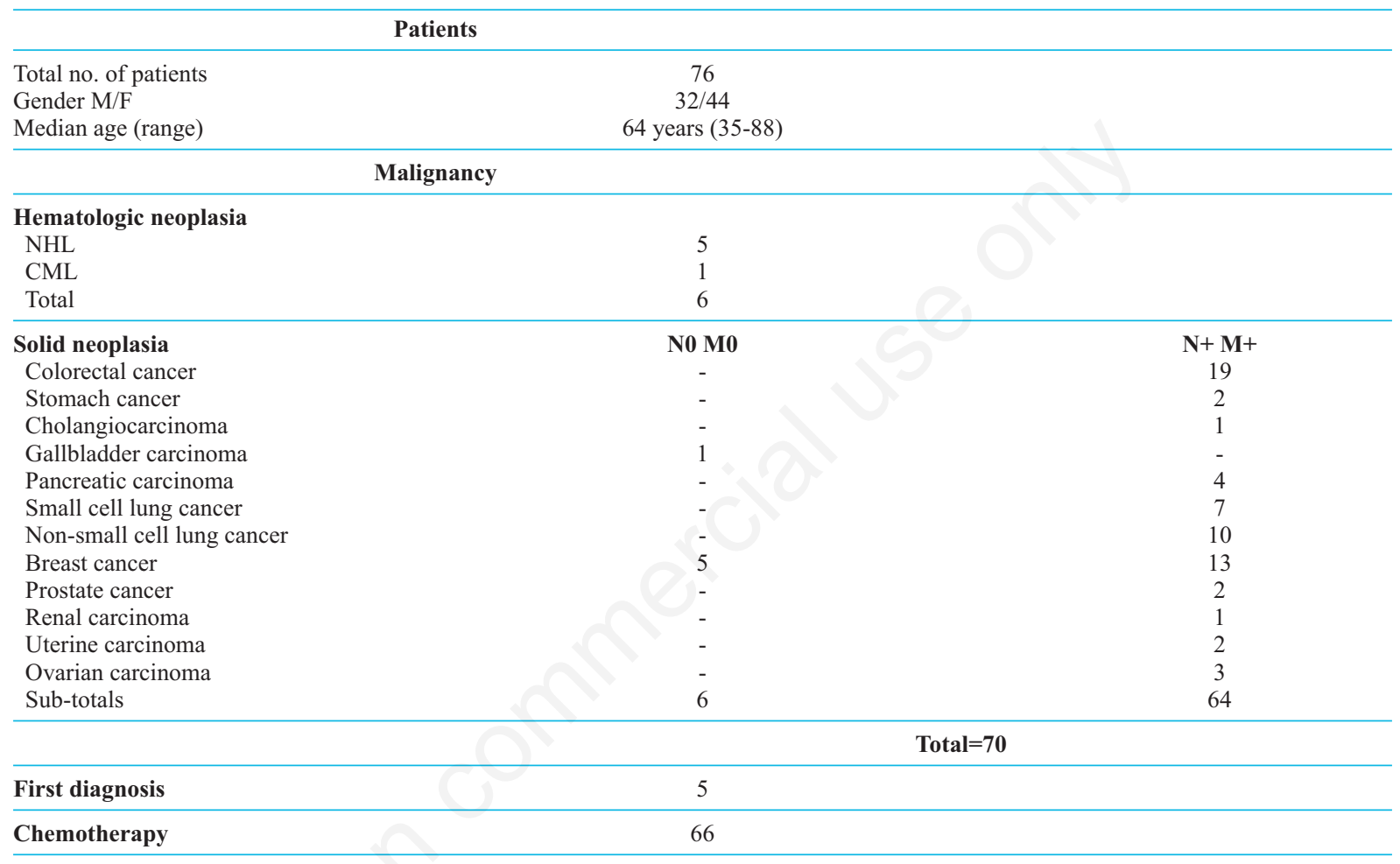

M, male; F, female; NHL, non-Hodgkin's lymphoma; CML, chronic myeloid leukemia; N0, no regional lymph node metastasis; M0, no distant metastases are found; N+ lymphnode metastases present $\mathrm{M}+$ distant metastases present.

Table 2. Patients' characteristics: non-active disease group.

\begin{tabular}{lcc}
\hline & Patients & 22 \\
\hline Total no. of patients & $5 / 17$ & 72 years $(35-86)$ \\
Gender M/F & Malignancy & \\
Median age (range) & & 1 \\
\hline & & \\
\hline Hematologic neoplasia & & 8 \\
NHL & 1 \\
Solid neoplasia & 1 \\
Colorectal cancer & 8 \\
Stomach cancer & 1 \\
Pancreatic neuroendocrine carcinoma & 1 \\
Breast cancer & 1 \\
Uterine carcinoma & & 1 \\
Choriocarcinoma & & 1 \\
Ovarian cystadenoma & \\
Total solid neoplasia & & 1 \\
\hline
\end{tabular}

M, male; F, female; NHL, non-Hodgkin's lymphoma. 
mean CRP value was $0.38 \mathrm{mg} / \mathrm{dL}$ (range $0.01-2.74$ ). The comparison between the two groups (patients with active and patients with non-active disease) showed no differences in baseline PCT, while there was a statistically significant difference between baseline CRP values $(\mathrm{P}<0.01)$. There was no statistically significant correlation between PCT and CRP levels in both groups of patients $(\mathrm{P}=0.05)$.

\section{Analysis of febrile episodes}

Twenty-one out of the 76 patients (28\%) with active cancer developed fever. In $90 \%$ of the cases, a bacterial cause was identified. The main sites of infection were: urinary tract (33\%), pneumonia (24\%), and documented septicemia (21\%).

The average PCT value found during febrile episodes due to a bacterial infection was $5.73 \mathrm{ng} / \mathrm{mL}$ (range 0.1-66.71), while the CRP average value was $10.2 \mathrm{mg} / \mathrm{dL}$ (range 0.34-32.32), i.e. 20 times over the upper limit of normal.

Hemocultures resulted positive in $30 \%$ of cases. Microorganisms identified were: Gram positive $(+)$ in 3 cases $(\mathrm{n}=2$ coagulase - Staphylococcus epidermidis, $\mathrm{n}=1$ Staphylococcus hominis - Streptococcus pneumoniae); Gram negative (-) in 2 cases $(\mathrm{n}=1$ Acinetobacter, $\mathrm{n}=1$ Pseudomonas aeuruginosa); and one Enterobacter aerogenes (anaerobic).

\section{Discussion}

\section{Basal procalcitonin values and cancer}

The first aim of our study was to assess PCT baseline levels in patients with active cancer. Among the few studies that have evaluated basal levels of PCT in active cancer patients, that published in 1989 by Ghillani showed high levels of PCT, but not of calcitonin, in neuroendocrine tumors and in hepatocellular carcinoma. ${ }^{8}$ However, the immunoradiometric method

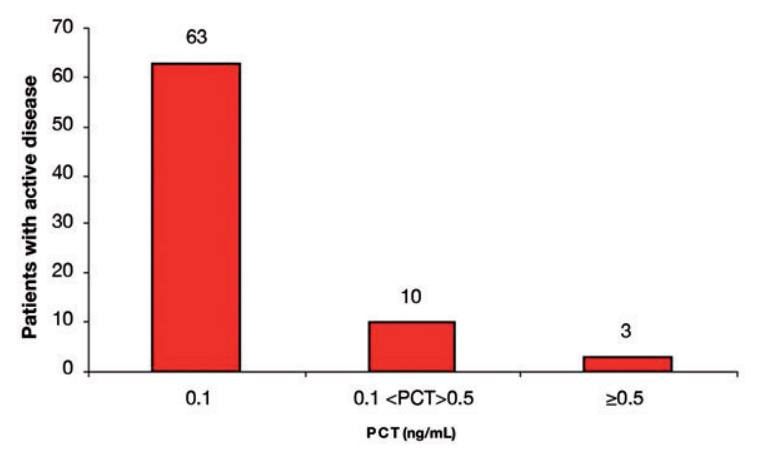

Figure 1. Baseline values of procalcitonin (PCT) in patients with active disease. used to assay PCT resulted less accurate than the test currently performed. In 2008, a prospective study on 61 patients with a predominance of hematologic malignancy was published by Prat et al. ${ }^{9}$ In these patients, baseline PCT levels were similar to those found in healthy control. In August 2010, a group of Swiss researchers published a prospective trial which involved 447 patients with solid tumors. In this study, all subjects, regardless of the stage and spread of disease, presented PCT values below $0.5 \mathrm{ng} / \mathrm{mL}$. The strength of this trial lies in its very strict inclusion criteria. Neuroendocrine tumors or equivalent (e.g. small cell lung), patients with severe renal failure, probable septicemia, and high CRP values were excluded. Moreover, in those patients in whom the suspicion of either an active infection or an inflammation could not be ruled out, positron emission tomography was performed. Therefore, the authors had concluded that there was no evidence of cancer having the potential to significantly alter PCT levels. ${ }^{10}$

The results collected in our observational study seem to demonstrate that tumors, whether solid or hematologic and even in the metastatic stage, do not increase PCT values. Furthermore, we observed that in oncological patients with active disease, PCT values are, in most cases, equal to $0.1 \mathrm{ng} / \mathrm{mL}$. This cut-off value is even stricter than that used by Giovanella et $a l .{ }^{10}$ In fact, some bacterial infections, especially those caused by an atypical germ, are known to induce a less obvious rise in PCT level, within a range of 0.2-0.5 $\mathrm{ng} / \mathrm{mL}$.

PCT values over the negativity cut-off limit of 0.1 $\mathrm{ng} / \mathrm{mL}$ have been found in patients with both small cell and non-small cell type lung cancer, as in results in the literature and the exclusion criteria presented in the Swiss group study.

\section{Procalcitonin levels and metastatic cancer}

The second aim of the study was to assess whether there was a significant difference in PCT values between two groups of patients: those with non-active cancer and those with metastatic or active disease. A literature review found few data and these were very old (e.g. Ghillani et al., in the late 1980s). ${ }^{8}$ Only recently, Matzaraki et al., in contrast to past evidence, have reported a significant increase in PCT in a very small group of patients all with widespread metastatic disease. ${ }^{11}$ In our study, the active disease group was numerically bigger ( $\mathrm{n}=76$ subjects). Even though, within this group, we did not differentiate between those with widespread disease and those with local active disease, the mean PCT value and the percentage of subjects with a PCT higher than the cut-off level were similar to those registered in the non-active group. In the active disease group, the PCT value at baseline was $0.15 \mathrm{ng} / \mathrm{mL}$, while in the non-active 
group, this was $0.10 \mathrm{ng} / \mathrm{mL}$, with no significant difference between the two. Therefore, based on these data, we can argue that PCT levels do not rise or alter in the majority of tumors, except in the already mentioned neuroendocrine tumors and affiliates.

\section{Use of procalcitonin in the differential diagnosis of fever in cancer patients}

We have noted that the majority of cancer patients, whether with local or widespread active disease, show advanced or baseline PCT values that are only minimally altered, if at all. This makes PCT a suitable candidate to be used in the differential diagnosis of fever in neoplastic patients. This has been widely investigated in literature. Except for only two works which have presented negative results, ${ }^{12,13}$ most of the trials published in recent years have shown several favorable outcomes.

In a prospective study of 111 patients with hematologic disease, Schuttrumpf et al. described high PCT levels in patients with fever related to a documented bacterial infection, while PCT values were within the normal range in those patients with drug-related or tumor-associated fever. ${ }^{14}$ The results of AznarOroval's group's study on 79 patients with neoplasia, published in September 2010, are also in line with previous findings. ${ }^{15}$ Several studies have also focused on testing the effectiveness of measuring PCT values in helping the differential diagnosis of fever in cancer patients with neutropenia as a consequence of both a hematologic disease and/or a chemotherapy. ${ }^{9}, 16-18$

Jimeno et al. reported 104 consecutive febrile episodes in neutropenic patients. It was seen that, in bacterial infections, an increase in PCT value was well above that registered in patients both with non-infection fever and in those with only the clinical suspicion without microbiological confirmation. ${ }^{19}$ Similar data were published by the group of von Lilienfeld-Toal, even if a lower number of febrile episodes were observed and only in patients with hematologic malignancy. ${ }^{20}$ More recently, Massaro has confirmed these same findings and has also shown once again the very low specificity of CRP assay in this kind of patient. ${ }^{21}$

The third aim of our study was to investigate whether PCT could be considered a reliable marker of fever due to bacterial infection in patients with active cancer. From July 2009 to September 2010, we observed 19 cases of fever of bacterial etiology and all of them showed an increase in PCT values of up to 60 times the upper limit of normal. The small number of patients who developed fever did not allow adequate statistical analysis to be carried out, but the descriptive data observed are fully consistent with those reported in most of the scientific literature. We have also seen that, during sepsis, CRP values increased significantly (up to 20 times the upper limit of normal). By com- bining CRP values with PCT values, we can argue that during bacterial fever a parallel increase of both these two markers can be expected. On the contrary, in the presence of fever of non-bacterial origin, CRP values tend to rise much more than PCT levels. Moreover, CRP values can show a slight increase in those patients without fever but with active neoplasia, while PCT values in these same patients do not present any change. More research on the combined use of different markers for the differential diagnosis of various clinical situations (such as fever or dyspnea) is needed.

\section{Conclusions}

This study had some limitations, i.e. it was an observational study and involved only a limited number of patients (although more than those in other published studies). In spite of this, our study represents a small, but significant, contribution to support a more extensive use of PCT in oncology. It also allows some interesting observations to be made. Its main finding was the substantial negative values of PCT in cancer patients without an infection. Given this, we can argue that a baseline PCT level assay should be carried out in a subject with neoplasia on presentation. This could then be useful during the patient's follow up, especially when he or she develops a fever. In fact, if a fever occurs, any rise in PCT value can then be demonstrated, and this might become a key factor in recognizing a potential bacterial infection. On the contrary, it could also allow us to exclude a microbiological cause, and would, therefore, help the clinical team to provide the most appropriate therapy. As observed in several works of literature, as well as in our study, subjects affected by either neuroendocrine tumors or affiliates (small cell lung cancer in particular) should not be considered according to this train of thought because of their false positive baseline PCT values which are related to the tumor activity itself. Finally, even a single assay, such as PCT, must always be considered within the clinical setting first. Therefore, this marker has to be viewed as an additional tool to use in the differential diagnosis of fever in those particularly difficult conditions such as fever in cancer patients.

\section{References}

1. Penel N, Fournier C, Clisant S, et al. Causes of fever and value of $\mathrm{C}$-reactive protein and procalcitonin in differentiating infections from paraneoplastic fever. Support Care Cancer 2004;12:593-8.

2. Ciaccio M, Fugardi G, Titone L, et al. Procalcitonin leves in plasma in oncohematologic patients with or without bacterial infections. Clin Chim Acta 2004;340: 149-52.

3. Bracq S, Machairas M, Clement B. Calcitonin gene 
expression in normal human liver. FEBS Lett 1993; 331:15-8

4. Simon L, Gauvin F, Amre DK, et al. Serum Procalcitonin and C-reactive protein levels as markers of bacterial infection: a systematic review and meta-analysis. Clin Infect Dis 2004;39:206-17.

5. Christ-Crain M, Jaccard-Stolz D, Bingisser R, et al. Effect of procalcitonin-guided treatment on antibiotic use and outcome in lower respiratory tract infections: a cluster-randomized, single blinded intervention trial. Lancet 2004;363:600-7.

6. Christ-Crain M, Stolz D, Bingisser R, et al. Procalcitonin guidance of antibiotic therapy in community-acquired pneumonia: a randomized trial. Am J Respir Crit Care Med 12006;74:84-93.

7. Schuetz P, Christ-Crain M, Thomann R, et al. Effect of procalcitonin-based guidelines vs satandard guidelines on antibiotic use in lower respiratory tract infections: the ProHOSP randomized controlled trial. JAMA 2009;302:1059-66.

8. Ghillani PP, Motté P, Troalen F, et al. Identification and measurement of calcitonin precursors in serum of patients with malignant diseases. Cancer Res 1989; 49:6845-51.

9. Prat C, Sancho JM, Dominguez J, et al. Evaluation of procalcitonin, neopterin, C-reactive protein, Il-6 and Il8 as a diagnostic marker of infection in patients with febrile neutropenia. Leuk Lynphoma 2008;49:1752-61.

10. Giovanella L, Suriano S, Ricci R, et al. Circulating procalcitonin in aseptic carcinoma patients: a specificity study with (18)F-fluorodeoxyglucose positronemission tomography/computed tomography as benchmark. Clin Chem Lab Med 2010;48:1163-5.

11. Matzaraki V, Krystallenia I, Alexandraki, Kyriaki Venetsanou. Evaluation of serum procalcitonin and interleukin-6 levels as markers of liver metastasis. Clin Biochem 2007;40:336-42.

12. Ciaccio M, Fugardi G, Titone L, et al. Procalcitonin levels in plasma in oncohaematologic patients with and without bacterial infections. Clin Chim Acta 2004; 340:149-52.

13. Penel N, Fournier C, Clisant S, et al. Causes of fever and value of C-reactive protein and procalcitonin in differentiating infections from paraneoplastic fever. Support Care Cancer 2004;12:593-8.

14. Schuttrumpf S, Binder L, Hagemann T, et al. Utility of procalcitonin concentration in the evaluation of patients with malignant diseases and elevated C-reactive protein plasma concentrations. Clin Infect Dis 2006; 43:468-73.

15. Aznar-Oroval E, Sanchez-Yepes M, Lorente-Alegre P, et al. Valor diagnòstico delaprocalcitonina, lainterleucina 8 , lainterleucina 6 y laproteìna $C$-reactiva en la detecciòn debacteriemia y fungemia en pacientes con càncer. Enferm Infecc Microbiol Clin 2010; 28:273-7.

16. Engel A, Steinbach G, Kern P, Kern VW. Diagnostic value of procalcitonin serum levels in neutropenic patients with fever: comparison with interleukin-8. Scand J Infect Dis 1999;31:185-9.

17. Carnino L, Betteto S, Loiacono M. Procalcitonin as a predictive marker of infections in chemoinduced neutropenia. J Cancer Res Clin Oncol 2010;136:611-5.

18. De Bont Es, Vellenga E, Swaanenburg J, et al. Procalcitonin: a diagnostic marker of bacterial infection in neutropenic cancer patients with fever? Infection 2000;28:398-400.

19. Jimeno A, Garcia Velasco, del Val O, et al. Assessment of procalcitonina as a diagnostic and prognostic marker in patients with solid tumors and febrile neutropenia. Cancer 100:2462-9.

20. von Lilienfeld-Toal M, Dietrich MP, Glasmacher A. Markers of bacteraemia in febrile neutropenic patients with haematological malignancies: procalcitonin and IL-6 are more reliable than C-reactive protein. Eur J Clin Microbiol Infect Dis 2004;23:539-44.

21. Massaro KSR, Costa SF, Leone C, et al. Procalcitonin (PCT) and C-reactive protein (CRP) as severe systemic infection markers in febrile neutropenic adults. BMC Infect Dis 2007;7:137. 